\title{
Surveillance en la Frontera: the Subversive Installations of Mexican Digital Artists Raphael Lozano-Hemmer and Alfredo Salomon
}

\author{
Reynaldo Thompson, Jorge A. Martinez-Puente, Diana Marañon, Jessica \\ Andrea Sanchez \\ School of Digital Arts, Universidad de Guanajuato, Mexico. Email: thompson@ugto.mx
}

\begin{abstract}
Political ideology is now made manifest and even palpable with a perverse articulation of digital technique, for once on its own, and without the need of any kind of narrative. Art by itself is enough. The ideologue is relegated to an unimportant location following a praxis that evades primordial dependence on the conventions of any discourse. Starting from a discussion of two important video installations by Rafael Lozano-Hemmer, this article proposes how the critical use of technology in contemporary art establishes a space, in an interpretive manner. The first section of the paper deals with the notion of subversion of technological devices deriving partially from Lozano-Hemmer's exploitation of technological praxis as a means of unmediated valorization of ideology. We analyze the metamorphosis of symbols into "fact" within the image, as a detonator of the simulacrum. The second section deals with Justicia Infinita of Alfredo Salomon, based in Puebla, Mexico and perhaps the most ingenious ideologue and artist of the digital era. In Salomon, just as in Lozano-Hemmer the process of subversion of technological devices and its bizarre yet comical inversion is still so powerfully visible. To conclude we shall turn to the implications of the critical use of technology in contemporary art and their ability to allow us to assume their ontological consequences.
\end{abstract}

Keywords: Contemporary art, metamorphic image, simulacrum, digital art, video installation, control societies, visibility, critical space, individuals, relational architecture.

\section{INTERACTION, DATA, ART AS MEDIA}

One of those great impulses of contemporary art is reflected in the desire to generate relationships with a multiplicity of socio-cultural phenomena that occur in discrete times, territories, and dimensions. In the words of Deleuze and Guattari such times and spaces are manifested as machine connections (Deleuze and Guattari 2005). This implies that the artistic product, like a machine, acquires meaning and functions like a node in a context of relationship with other artistic symbols creating, what Deleuze further calls, a psychiatry of machinic connections. Just as machine functions in a system of interconnected machinery and other sources of energy, so does art - like a motor connected to a turbine, which is further connected to grids and powerhouses, which further connect to other distant terminals. The work of art is often generated in a system of data-sets that comprise an algorithm for the expression of a function in a network of relationships. Here we shall analyze such relationships in Dan Flavin's installations

(c) AesthetixMS 2019. This Open Access article is published under a Creative Commons Attribution Non-Commercial 4.0 International License (http://creativecommons.org/licenses/by-nc/4.o/), which permits non-commercial re-use, distribution, and reproduction in any medium, provided the original work is properly cited. For citation use the DOI. For commercial re-use, please contact editor@rupkatha.com. 
and Raphael Lozano-Hemmer's Under Scan and Close-up which were conceived by LozanoHemmer in 2005 and 2006 respectively, and then finally in the Justicia Infinita (2003) of Alfredo Salomon, which is also again an ingeniously provocative digital installation that was exhibited for the first time in Mexico City. The interplay between the human viewer and the technological medium of art results in a subversion of technological devices. If we focus on Close-up or Justicia Infinita to look specifically at the techne (Aristotle) of contemporary art, we now see how it becomes a functional process, and - a critique or statement of purpose. But why refer to Aristotle? The conceptual element of techne as stated in Book VI of Nichomachean Ethics, like the power of metamorphosis inherent in the Ranciere image, represents an instrument of knowledge. The technological aspect of the art shows how images are capable of liberating messages that were previously only limited to political relationships (Ranciere, 2011, p 44). Interplay between viewer and artwork (in Dan Flavin) entails not only display and realization of a simulacrum of meaning (Perniola, 2011, p 27), but public participation (as opposed to subjective creation) in the generation of symbolic images. Similarly for Lozano-Hemmer and Alfredo Salomon the consumer of art is no longer a passive recipient of a communicative act. Their representations are conditioned by data inputs from the viewer, as they watch and react towards the installation, in a space, which secures their participation. The production of an interactive installation results in an amplified and modal subversion of conventional techniques of representation. In Lozano-Hemmer the object of art shall look like how the audience responds in front of sensors embedded in the installation. The viewed objects keeps changing and subverting expectations. We shall consider the implications surrounding such artistically significant subversion of technology so that we could re-affirm new procedures - a new praxis - that could help human beings assume the ontological consequences of technology, especially in contemporary art.

Consider how Foucault also expresses what he calls an unabated and unchanging panopticism is destined to spread and contaminate the entire social body: how its vocation is to become a generalized function, a pseudo-normative view. Deleuze also calls the illuminated, post-industrial urbanscape as one essentially resembling any other society of control (Deleuze 2006). Appearance prevails in the new media technologies like the "... lines of light that form variable and inseparable figures of this and that device” (Deleuze et al, 1999, p 155). The numerical language of control in such societies is based on the data that mark the entry or rejection of information. As Gilles Deleuze suggests the purpose of Foucault's subject is to become: "the one, the all, the true, [where] the object, or the subject are not universal, but singular processes of unification, of summing up, of verification, of objectification, of subjectification, or inherent processes of a device" [our italics] (1999, p 158). In the critical space of societies of control: "we are not here before the 'individual-mass' pair. Individuals have become "dividuals" (1999, p 281), meaning, datainput units, and passwords, "simultaneously when the masses might have become indicators, markets, 'banks' (1999: 281). The Mexican philosopher Pablo Lazo also identifies such normative visibility in societies of control as if they were placed on a continuum; from the perspective of multicultural panopticism these images could be understood as a uni-dimensionality of cultural practice and as if they were arranged in relation to mechanisms of dissemination by some central media like the television or satellite communication - media which could function across borders and territories, with indifference and totalization.

\section{FLAVIN AND THE BEGINNINGS OF CRITICAL TECHNOLOGY}

The term installations was reportedly used for the first time by Dan Flavin in 1969 to name a work that he invented; it consisted of neon tubes located in different rooms of the exhibition gallery. 
This first example of the genre suggests that installations refer to an open art concept in which both space (here the rooms in the gallery) and the observer (visiting the rooms and literally connecting the spatially discrete images of neon) have a fundamentally engaged role to play in the formation of the art 'object'. The installation is an open form in art that expresses multiplicity and connectedness, though in this article we shall concentrate on the unpredictable openness or directionality of installation-art where the technological devices used to create a project gets perverted and disjointed. The technological media links to what we might call a subversion of components and devices leading to construction or perdition, depending on the angle from which we are looking at it. The devices move towards the creation of an unforeseen, critical, nonteleological interactivity, a platform which cannot be defined in terms of any stable ontological paradigm. The artist succeeds in showing that his creations are based on critical use, and understood only in terms of the appropriation and translocation of technology. Computerized surveillance systems and telematic networks operate like props driven by variation and randomized inputs. Surveillance cameras detect random content depending on the moment involving public participation for the interactive system of the arts. Appearance (rather than reality), at a given point in time then occurs like the conceptual indicator for understanding a work like Dan Flavin as an act as Revel says, “... of resistance against the actual devices of power, emphasizing the critical dimension of the created gesture" (Revel, 2009, p 30), as if it were destined to be so because of the subversion of the technological devices it was using.

\section{RELATIONAL ART AND THE SUBVERSION OF TECHNOLOGICAL DEVICES}

Following Flavin we might as well identify subversion of devices as the endemic, exacerbating and putrefying pseudo-didactic pit of art, a bizarre rather than sublime genre uniquely depending on a completely pernicious process of identification or being for the realization of unnatural but semantically disturbing forms of art. Lozano-Hemmer himself mounted several videoinstallations in which the strategy of deploying incorrect technology is made almost palpable in its effects.

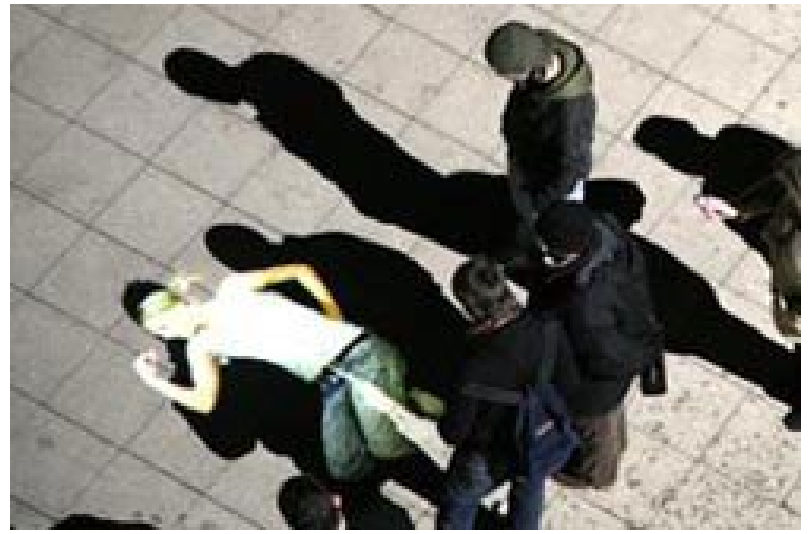

FIGURE 1. Rafael Lozano-Hemmer, Under Scan, United Kingdom (2005). Photos from Antimodular Research, courtesy of the artist.

Under Scan (Fig. 1) is the expression of Foucauldian appearance, and of positioning the subject (i.e. the viewer) so that one must bear an image generated by the overlooking surveillance mechanism. The installation is conceived like a surveillance mechanism consisting of an almost accidental video projection of images on the floor of the gallery. However, these projections are video-portraits previously recorded from an optical interplay with about 1000 volunteers. This 
"exhibition" functions theoretically like a parody of Foucauldian Panopticism, in which shadows fall upon the floor like caricatures of the implausibly dark, and denatured shadows cast out of the panopticon. The shadow-images of the floor become versions of Lozano-Hemmer's simulations of a typically subtle and humorous normalcy, only to accentuate its differences from the Other, which is portrayed by cutouts or pictures of bodies superimposed like layout prints on the ground. Therefore, the subverted, parodic, and declassified or incorrect grammar of surveillance technologies starts to reveal a dynamics of visibility and expose ideologically reverse codes. Subversion of control technologies, "no longer abandons nor assumes an interdiction, a rule or a law, but takes the detour, the wrong path, (of) corruption" (Kristeva, 1988). Under Scan exposes how the machine modulates surveillance as an experience of a data or bank of information, in this case video-portraits and subjects. Instead of the classic society of control a state of universal subjection sets in - as if it innately belongs to technology as a thing-in-itself. This also means that in terms of aesthetics the epistemological function falls upon media technologies. The change in epistemological function that is incumbent on the new, denaturalized communicative technology spells also even the end of a Foucauldian regime only to introduce a discourse of technological subversion. Interactivity, media algorithm and stochastic possibilities are unpredictable drives that function in an arbitrary manner, subverting power relationships that sustain existing economies and the status quo.

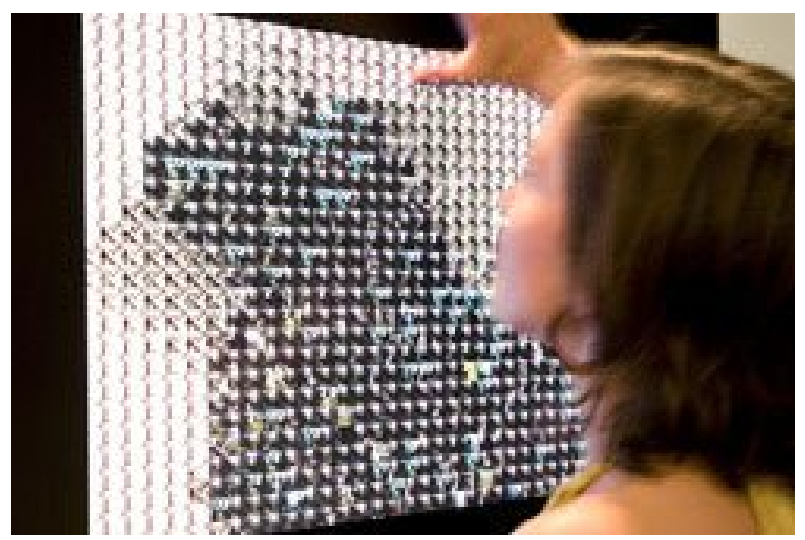

FIGURE 2. Rafael Lozano-Hemmer, Close-up, United States (2006). Photos by Antimodular Research, courtesy of the artist.

Argentinian anthropologist Paula Sibilia commented that:

In the meanders of the cyberspace new practices that are difficult to catalogue germinate all over the globe, and gets inscribed in a nascent field of communication that is mediated by the computer. They are pretty varied rituals that overflow into all four corners of the world and do not cease to gain new followers day after day. (Sibilia, 2008, p 15)

We propose that the kind of media that Sibilia describes is indeed difficult to catalogue but it turns to be what it is because of the perverse utilization of the medium that allows the technological artist to create environments and body languages of one's own. Lozano Hemmer, quite famously, and unlike what Flavin did in 1969, does not define his video-installations but merely calls them relational architecture or specific relational art in order to divest it from concretization and its visual correlates, and indeed from the accustomed fidelity to all forms of construction, and even of the materially non-existent conditions of virtual reality and its concomitant imagery. 
We should take into account the fact that for Flavin the installation constitutes the architectural space, which was as important as the visible and hypostasized work itself. In Flavin works the "enclosed" space defined the shape, length and the color of the piece in order in the sensoriality of the lights associated with the industrially produced fluorescent bars; while in Lozano-Hemmer it was, thanks to the rapidly evolved technology, installations were delimited by facades or pavements in the cases studied here or like in many other works of his in the emergent beam of light trying to reach infinity (Vancouver). Space perception, psychological and political, is an intrinsic element in both forms of installation: in Flavin it is contained in an enclosed room space while in Lozano-Hemmer in an open one - though in both cases a phenomenology of perception (Merleau-Ponty, 2002, p 421) may be of great use for its understanding.

We must therefore rediscover, after the natural world, the social world, not as an object or sum of objects, but as a permanent field or dimension of existence. [our italics] (MerleauPonty, 421)

Merleau-Ponty's assumption ignites the focus of our analysis in the fact that in Flavin's work, his focus was more oriented towards the perception of the colors emitted by the fluorescent light, while in Lozano-Hemmer as well as in Alfredo Salomon's that we shall study in the coming pages there is a strong criticism in their representation of modern forms of surveillance, realized in terms of data interplay of lights and invisibility, fluorescence, obscurity, vigilance and discontinuity.

\section{CRITICAL MEDIA, AND SUBVERSION: LATIN AMERICAN PERCEPTIONS}

It was Ranciere, rather than Sibila who was more concerned with the historical project of constructivism or symbolism in which art liberated image from its meaning; post-symbolic technology finally also leads to the recognition of artistic signification in other areas of action (Ranciere, 2011, 29). The constructivist and symbolic project has driven the image to acquire a more indeterminate simulacrum; according to Argentinian thinker Mario Perniola it is not possible for the contemporary image to have any symbolic character due to its skeptical and nihilistic conditions which rescind concreteness and create lack: in any simulacrum whatsoever (Perniola, 2011, p 27). A new identity of contemporary art gets to be visible - one which is defined only in relation to technology. In the new stages of video-art for example, the symbolic image allows us to jump and explore other forms of expression in the techne of the image. Contemporary video art refers to the impulse of a particular fact with which one can play and test, searching other possibilities or facts related to the wide optical array of the installation so that its integral moment now reveals a metamorphosis of the image. For Ranciere at least this precisely was a metamorphosis of the image, "There is no singular nature of images or of art that defines the similarities and discursive meaning of the symptoms" (Ranciere, 2011, 44). Therefore, this metamorphosis shows us the unstable character of the image, which only leaves us with the undecided task of playing with the ambiguity of their similarities and the instability of their differences. In such a way a perverse metamorphosis proves how artists explore and question the radical nature of the image, through the game of shapes and the bits of the imaginary, all resulting in a reorientation that even no theory of symbolism in the early twentieth century could anticipate.

For Close-up Lozano-Hemmer first captures visual images of the participating viewers of the installation and then uses this visual data to make representations. The archival record of data collected by video engages participants who view and interact with the work. The visual data-sets 
simulate and reduce reality to a game of data codification, allowing the participants to be simultaneously participant and representation. The result is a combination of and convergence of information. Here as well the work is only made intelligible as a control mechanism that exploits a domain. Random participation of the intervening spectators who at the same time act as data and user; all this with the purpose of achieving a re-ordering of surrounding images or realities, which are like imaginary products of the artist. Additionally in Close-up the nature of the images correspond to the ambiguous game of data for its creation. Therefore, instead of using the pencil, or light or body the tools used are the data from participants, perverting the use of any given medium based on the terms and shape of knowledge. The technology itself questions the spectators and perturbs the daily circulation of image and its circulating realities; the images frustrate the proper order in which they may appear in the aesthetic or political spheres of reception and activity. In this way the collection and organization of spectator-data helps in creating a mathematical algorithm that allows simulation, and the production of an artistic object, converting the artist not into the creator of the work, and nor its user, but into an agent in an environment, such as paradoxically Baudrillard predicted when he affirmed that the modern creator (like an engineer perhaps) is not a consumer or owner of his objects, but only in charge of its management (Baudrillard, 1981, p 26).

\section{JUSTICIA INFINITA}

The eerie simulation of an artificially intelligent gun devised by Alfredo Salomon, in an installation titled Justicia Infinita, was exhibited in a public forum in Mexico City in 2009. Justicia Infinita deserves to be classified as one of the most significant installations of the digital millennium; the project consists of a hypnodrome which is none other than a technically space crafted out of the space of the museum. The main context on which Justicia Infinita fits is that of surveillance again - but more specifically it has its bearing on the decision taken by the Bush administration to launch the defense project Infinite Justice on Iraq following the attacks on the Twin Towers in New York. The piece was developed on mono band video and some of the artistic influences come from José Luis Garcia Nava who explored the idea of having a gun in a gallery. In Justicia Infinita the robotic program was written by Ricardo Cortés who is a musician and artist; part of the project was supported by Julian Cerón (who were all working at the Centro Multimedia of the Centro National de las Artes in Mexico City). The economic support for the piece came from the Rockefeller Foundation as well as from the FONCA (Fondo Nacional para la Cultura y la Artes in Mexico). The pieces was shown at the CENART (Centro Nacional de las Artes) because it was necessary to drill the floor to install the interactive gun and most galleries were not ready to allow drilling the floor. The artwork was also shown at the Galería Trama of Guadalajara. In Salomon's piece we see how he wanted that the aggressor also became the victim. It also was a response to a possible world conflict, in this case the war would be a smart war controlled at a distance by robots and tele directed. Powered by a mechanism of sensors the digital hypnodrome invites the performing viewer only to trap him, and to follow him till a point of time in which the gun reveals itself out of darkness and occlusion. The tragicomedy characteristic of high art is written into this installation: as Salomon himself says "It is a robotic video installation, a reflection of violence, and violence with fire weapon. The space is totally dark for the viewer, even though it is covered with infrared light and this weapon is always pointing at the person... entering this dark space where no one knows what is going to happen is the first obstacle that he should overcome, and the second is to confront the weapon." (The video clip can be seen in YouTube). 


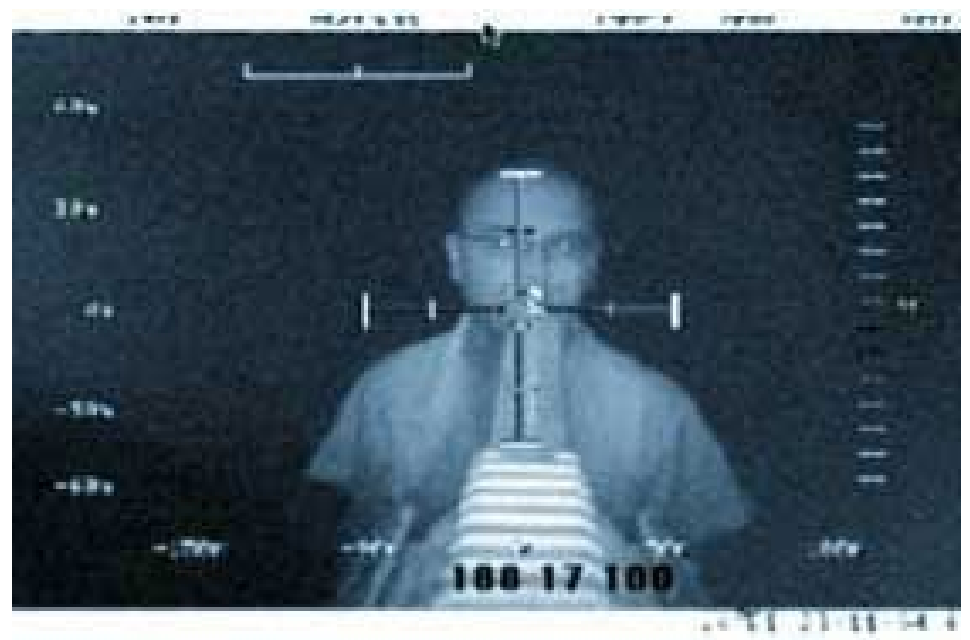

FIGURE 3. Artist seen through the surveillance camera. A moment in Justicia Infinita (2003) by Alfredo Salomon.

A screen opposite to the gun displays exactly what the gun sees, in this case the human being which is a moving target, and then it poises to shoot its victim like a personification of the imminent nemesis. No doubt the digital object precipitates a crisis of humanity for the victim, raising in the process the spectrum of H.G Well's Big Boss, the ubiquitous observer of human actions in a sci-fi world, and all the characteristics of Foucault's panopticon. The installation is a traumatic experience where hunter and pray are confined in an immersive, dark and enclosed space.

Justicia Infinita defines the characteristics of digital art not merely from Po-Hsien Lin's perspective of an ontological description of digital imagery (Lin, 2005, p 4-12)- but by manipulating the implications of the design for an ethnographically significant event. Could Digital Art have an ethnographic function for electronically literate societies? Thus even as we acknowledge the importance of such studies as those investigating digital praxis by using ideas and strategies of cybernetics or digital coding (Abraham Moles' path-breaking interdisciplinary exploration called Théorie de linformation et perception esthétique (1958), for example, or the later, more politicized perspective of Paul Virilio's essay titled "The Sight Machine" in the War and Cinema: The Logistics of Perception (1989), we can discuss the question of digital art in the framework of emerging posthuman literacies or what we might call e-culture; even under the economic structures which drive populations through new technologies and competing ethnic alignments. Perhaps the most spectacular effects in this realm of digital installations have been achieved in Mexico, and other parts of Latin America. Already familiar with the more specific topos of robotics -Salomon's installation Justicia Infinita seems alone and most potently to have produced imagery of post-Gulf War. In fact the Sinergia Tecnológica project of the time attracted artists to the CENART in Mexico City, for a series of stimulating digital art productions committed to the exploitation of the digital uncanny in a pseudo-comical manner, and for the transmission a political message. Salomon's art plays with infrared light and invisibility providing a sudden unexpected antidote to the kind of anodyne art that late capitalism could wholeheartedly embrace. It is an art that would encourage critical reflection in the viewer. This is like the description of installation as a sort of distraction for mass society and as a kind of interactive, cathartic experience, as Claire Bishop wrote about installation art, an art described often as theatrical, immersive or experimental as in this case, taking technology to alternative level so that it becomes perverse, comical, frustrating - like an irritant, the gun now forces the 
viewer into reaching out for capacities on the other end of light and its spectrum, like into inside of a field where we do not know what will happen on the face of our capitalist certainties (Bishop, 2010, p 8).

\section{CONCLUSION}

\section{TECHNOLOGY, SUBVERSION AND LOGOS OF CONTEMPORARY EXISTENCE}

In conclusion, we can affirm that the dynamics of data collection for the construction of any product is one of the paradoxical constants of contemporary art. Public interaction becomes data and forms a network from which a resultant pattern of images or objects are generated. Within this logic, the artist creates works based on the creative use of spectators/participants, generating a game of tension, recognition, and dependence between spectator and artist. However, the participative nature of contemporary art and its relation to technology not only represents a political project or emancipation of control societies and the spectacle. On the contrary, it becomes one more strategy that allows creation of an opposition to visual art: a reflection and question around appearances (Bishop, 2012, p 283-284). In this way critical space of contemporary art shows how the techne operates like a strategy and how the art thus acts as an epistemic process of knowledge and ideology. Therefore this inclusion of new areas and discourses around contemporary art allows us to amplify the capacity to imagine and question the relation between art, technology, and our way of being in the world through the seemingly incomplete processes of experimentation and innovation.

These new specters of Lozano-Hemmer's relational arts and Salomon's machine surveillance techniques propose ontological mechanisms in the form of visible tools. They seem to have been destined as processes embodying or deciphering the meanings of the age. The new imagination that we discuss here entails changes in the aesthetic material, such as changes in space and time and the conventional Kantian categories. For Kant space and time were subjective formations, for digitally interactive art, they are products of collective data-sets that change our expectations of a linear and predictable shape for space or time. The coordinates for an installation are never fixed, configurated symbols like a museum piece, but are always changing variable formations. These changes presuppose the form of an art, which does not fit within the already established criterion of immobile creativity. The dialogue between art and technology helps us imagine new possibilities and spaces. The physical material of any aesthetic perception may be made out of practically anything. For example in Under Scan the physical material that is used to design the piece are people - the raw stuff of human society, whose presences are like the shadows and pictures merely transformations of the same people by telepresence and like reproductions in light emitted by projectors.

Logos and techne converge to demonstrate both human and aesthetic components the concept of praxis we propose has to be understood as the practice that characterizes the human perceiver or enactor's dimensions as an active and creative being. This praxis is the foundation of their aesthetic relationship with reality, and at the same time, it is action and transformation of nature, which is not required pure and simple for the need to subsist - as a natural instinct - but for the need to re-affirm humanity. This praxis will act as the media for creation or establishment of a new exterior and a new interior reality, that forms part of the aesthetic knowledge now forged in a historical and social way in the process of the transformation of nature, which is not required purely and simply for the need to survive - like a natural instinct - but for the need to affirm one's true humanity. The relevance of praxis, which gives us our humanity and at the same time 
contains the capacity of change may not need theorizing at all. Therefore, what is of importance for all practicing artists is that they have their bases in the critical technology, and that they also reside in the cross between symbol and techne, to be able to touch spectators hearts, so to speak. However, we should point out that the historical-conceptual moment in which pieces such as Lozano-Hemmer's or Salomon's are developed may depend on who possess the technological tools and who appropriates the logos.

Despite this, our generation has recovered from that original prejudice that relegated technique to a hidden and uncompromising subjectivity. But now subjectivism, intention, doctrine fall apart because the argument that the sender and receiver are opposite entities is now invalid. These practices demonstrate that the interactional techne dominates reality, a doubtable argument when we realize that only through the aesthetic experience given through logos is it possible to recuperate the relationship of technology with human beings. The new sensibility emanating from the cross between art and technology, will start to demand a historic analysis that brings the reconsideration of the system of arts, and meaning: a new analysis is required from the structure of the artistic pursuit in terms that construct a systematic theory which could judge the new with adequate parameters. All this represents a new direction in the study of the arts, as it proposes fundamental ontological question from new artistic practices, such as the real need of physical reliefs for perception. We may say that technological criteria in contemporary art is realized when control devices are perverted and the image is muted. Art transgresses the criteria of stable and universalist assumptions of knowledge or science. However, for this to happen the older categorical processes of techne and logos must converge in a critical space, as a subversion of the control devices that provokes change in the aesthetic material. "Subversive" is a keyword: it anticipates a new orientation in the discourses and appearances in our era. So it is perhaps no longer necessary that we construct a theory apart from this kind of subversion which is already spreading out.

\section{References}

Baudrillard, Jean. (1981). El Sistema de los objetos. México: Siglo Veintiuno Editores, México, 26

Bishop, Claire. (2010). Installation Art. London: Tate.

Bishop, Claire. (2012). Artificial Hells: Participatory Art and the Politics of Spectatorship. London: Verso Books, pp. 283-284

Coulter-Smith, Graham. (2006). Deconstructing Installation Art. Fine Art and Media Art 1986-2006. London: CASIAD, 1

Deleuze, Giless, H.L. Dreyfus, M. Frank, A. Glucksmann. (1999). Michel Foucault, Filósofo Barcelona: Gedisa, 155

Deleuze, Gilles and Guattari, Félix. (2005). Rizoma. Valencia: Pre-textos.

Deleuze, Gilles. (2006). Conversaciones Valencia: Pre-textos,

Gordon Monro. (2009). "Emergence and Generative Art" Cambridge: MIT Press

Kristeva, Julia. (1988). Poderes de la perversión. México: Siglo XXI, 25

Lin, Po-Hsien. (2005). A Dream of Digital Art: Beyond the Myth of Contemporary Computer Technology in Visual Arts. Visual Arts Research, Vol. 31, No. 1, Intersections of Technology with Art Education Champain: University of Illinois Press. pp. 4-12

Lizarazo, Diego, Echeverría, Bolívar y Lazo, Pablo. (2008). Sociedades icónicas. México: Ed. Siglo XXI 
Merleau-Ponty, Maurice. (2002). Phenomenology of Perception. London: Routledge, 421

Perniola, Mario. (2011). La sociedad de los simulacros. Buenos Aires: Amorrortu, 27

Rancière, Jacques. (2011). El destino de las imagines. Buenos Aires: Prometeo Libros, 44

Revel, Judith. (2009). Diccionario Foucault. Buenos Aires: Nueva Visión, 30

Sánchez Vázquez, A. (2005). Las ideas estéticas de Marx. México: Siglo XXI, México.

Sibilia, Paula. (2008). La intimidad como espectáculo. Buenos Aires: Fondo de Cultura Económica,15

Alfredo Salomón. (2009). Justicia Infinita. Retrived from: https://www.youtube.com/watch?v=yNOBzZrknno

Rafael Lozano-Hemmer. (2005). Under Scan. Relational Architecture 11. Retrived from: http://www.lozanohemmer.com/under_scan.php

Rafael Lozano-Hemmer. (2006). Close-up. Shadow Box 3. Retrived from: http://www.lozanohemmer.com/close-up.php 